\title{
The Research of Crew Workload Evaluation Based on Digital Human Model
}

\author{
Yiyuan Zheng and Shan Fu \\ School of Aeronautics and Astronautics, Shanghai Jiao Tong University \\ 800 Dongchuan Rd., Shanghai 200240, P.R. China \\ zodiac_leo@126.com
}

\begin{abstract}
The present paper presented the requirements of a digital human model used in the research of human factors in flight deck design and the methods to assess the workload, and established one model to evaluate the crew workload based on certain task.
\end{abstract}

Keywords: Digital Human Model, Human factors, Fuzzy Model Identification.

\section{Introduction}

Aircraft accidents have always been the major safety crisis to the aviation industry. According to NASA's statistics, over $70 \%$ of these accidents could be attributed to the performance of man. Therefore the research of human factor is important to the safety of the aircraft. To correct the errors $h$ happened in preliminary design phrase would cost much more time and efforts in detail design phrase, thus the human factor should be considered seriously at the beginning of the design, especially in the cockpit design, for over $90 \%$ flight operations are accomplished there.

Currently, the majority of the researches of human factor in aviation were carried out with the concept of aviation psychology. Although these measures are fairly reliable, it results from the accidents and catastrophes. Therefore, it is reasonable to study the human factor from the perspective of engineering design with digital human as the role of pilots.

\section{Construction of Digital Human}

Currently, digital human models have been wildly used in different fields like training, risk assessment and UI design. There are lots of benefits of using them in the engineering design and human factors engineering, such as shorter design time, lower established cost and increasing quality. It narrows the gap between engineering and ergonomics, and realizes human-centered concept in the design process.

\subsection{Requirements of Digital Human}

Digital human model in the aviation industry, especially researching human factors in the flight deck, is an emerging technique. Based on the specifications and activities of the pilots, the development of such digital human model should consider the following features related to the physical and behavioral attributes or requirements of real pilot: 
- Coverage: The range of pilot selection is 5\%-95\% of normal people. [1]

- Visibility: The pilot's angle of view of outside sitting in normal position is at least $15^{\circ}$.

- Comfort: Whether the seat is comfortable enough directly influence the behaviors of the pilot.

- Accessibility: Make sure that the digital human models could reach and operate each switch easily.

- Ingress and egress: Make sure the target could get in and out the cockpit easily.

- Cooperation: Whether the performances of the pilot or the co-pilot could affect the other one that would influence the performances of aircraft?

- Decision making: Such digital human model should have basic mental characteristic of human.

\subsection{Construction of Digital Human}

Beside the above requirements, the established digital human model should subject to the basic physical parameters of pilots. As a special career, pilot has its own specifications, as following table giving out the main dimensions of male pilots in China:

Table 1. Main dimensions of male pilots in China

\begin{tabular}{|c|c|c|c|c|c|}
\hline $\begin{array}{c}\text { Monitoring } \\
\text { Items }\end{array}$ & Monitoring Items & & Monitoring Items & \\
\hline Height $/ \mathrm{mm}$ & 1720 & Eye height $/ \mathrm{mm}$ & 1606 & Shoulder breath $/ \mathrm{mm}$ & 388 \\
\hline Weight $/ \mathrm{kg}$ & 71 & Shoulder height $/ \mathrm{mm}$ & 1402 & Sitting hip breath $/ \mathrm{mm}$ & 349 \\
\hline Upper Arm $/ \mathrm{mm}$ & 320 & Sitting height $/ \mathrm{mm}$ & 932 & Total head height $/ \mathrm{mm}$ & 233 \\
\hline Forearm $/ \mathrm{mm}$ & 238 & Sitting eye height $/ \mathrm{mm}$ & 819 & Hand length $/ \mathrm{mm}$ & 186 \\
\hline Thigh $/ \mathrm{mm}$ & 500 & $\begin{array}{c}\text { Sitting shoulder } \\
\text { height } / \mathrm{mm}\end{array}$ & 614 & Foot length $/ \mathrm{mm}$ & 254 \\
\hline
\end{tabular}

According to the parameters in table and concerned requirements, we built up a digital human with certain parameters in figure 1:

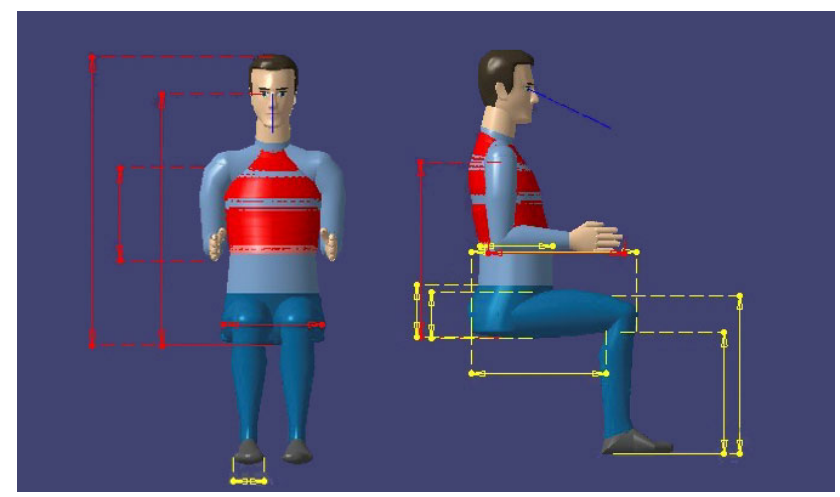

Fig. 1. The Standard Chinese Male Pilot Digital Human Model 
The visibility and accessibility analyses were carried out in a model of prototype of MA60, and the results were satisfied.

\section{Crew Workload Research}

The definition of workload can be described as the portion of human resources the operator required to perform a task under certain environmental and operational conditions. The resources reflect as physical and mental requirement of the operator. Appropriate workload might improve the efficiency of the operator, however, excessive workload definitely results in severe performance decrements.

Workload evaluation techniques are typically classified into three categories: subjective assessment, physiological methods and task performance measures. [2]

Task performance measures basically separate into two types: primary task measures and secondary task measures. Primary task is frequently used as the research of generalization of the study, while the secondary task itself has no practical means and only serves to measure the work load of the operator.

In order to make the primary task measures reliable, it is necessary to well-plan the parameters that should be measured. Frequently, primary task measures are worked out with combination of experimental and operational assessment, like speed, response time, accuracy and error rate are often served to evaluate the primary task performance.

We used primary task measures to evaluate the workload. The primary task was continuous portion of the operations of taking off which included 2 operations to mode control panel, 2 operations to overhead panel and 1 operation to CDU, and the parameters we selected to indicate the workload were average time to fulfill such task and the angle of rotation of shoulder joint of digital human, where Average Time is calculated based on the MOD method, [3] and Angle of Rotation relies on Human Posture Analysis in CATIA. After such simulation, we compared the results with data from experienced pilot who achieved the same task under the condition of semiphysical simulation to assess that whether the established digital human model was suitable for workload research.

\subsection{Measurement of Features of Digital Human and Determination of Evaluation Types}

Simulated the digital human models to obtain the average time and angle of rotation of shoulder joint by forcing the models to accomplish the above task, the data as following table:

Table 2. Measurement Results of Digital Human Model

\begin{tabular}{|l|c|c|}
\hline Digital Human Model & Average Time & Angle of Rotation of Shoulder Joint \\
\hline Standard Human Pilot Model & $7.5 \mathrm{~s}$ & $366^{\circ}$ \\
\hline
\end{tabular}

To giving out a comparative reference, we gathered five experienced pilots to discuss the type of the average time and the angle of rotation of shoulder joint according to their flight experiences. The consensus was following: 
Table 3. The type of behavior

\begin{tabular}{|l|l|l|}
\hline Type & Average Time & Angle of Rotation of Shoulder Joint \\
\hline Bad & $>7.8 \mathrm{~s}$ & $>390^{\circ}$ \\
\hline Common & $7.3 \mathrm{~s}-8.2 \mathrm{~s}$ & $355^{\circ}-395^{\circ}$ \\
\hline Good & $6.8 \mathrm{~s}-7.6 \mathrm{~s}$ & $340^{\circ}-370^{\circ}$ \\
\hline Excellent & $<7.2 \mathrm{~s}$ & $<360^{\circ}$ \\
\hline
\end{tabular}

\subsection{Fuzzy Model Identification}

Then, to analyze the workload, we used the Principle of Maximum Membership Degree. Assuming that the parameters of Average Time and Angle of Rotation of Shoulder Joint are following the normal fuzzy set, therefore, the relevant function of membership degrees is: [4]

$$
A_{j}=\left\{\begin{array}{c}
0,\left|x_{j}-\bar{x}_{j}\right|>2 s_{j} \\
1-\left(\frac{x_{j}-\bar{x}_{j}}{2 s_{j}}\right)^{2},\left|x_{j}-\bar{x}_{j}\right| \leq 2 s_{j}
\end{array}\right.
$$

Where $x_{j}$ is the parameter of Average Time and Angle of Rotation of Shoulder Joint, $\bar{x}_{j}$ is the average value of consensus, and $2 s_{j}$ is the standard deviation, then compare each $A_{i}(x)$ by the following function to determine the membership:

$$
A_{i}(x) \approx \frac{1}{2} \sum_{j=1}^{2} A_{j}\left(x_{j}\right)
$$

\subsection{Results}

According to the calculation, the membership degree of DH to 'Common' is 0.7444 , which is higher than the degree to 'good' that is 0.4499 . Therefore, we classified the performance of Digital Human to 'Common'.

The results of the model are in accordance with the expectations, and we thought the model could be used to evaluate the crew workload. In order to make the model more human, the mental part would be added to it.

\section{Conclusion}

In this paper, the author introduced the digital human models used to evaluation the crew workload of pilot, and established one to accomplish a given task. The results are in line with the expectations.

\section{Acknowledgement}

This research work was supported by National Basic Research Program of China-(973 Program No. 2010CB734103). 


\section{References}

1. Van der Meulen, P.A.: Perry Diclemente Ergonomic Evaluation of an Aircraft Cockpit with RAMSISI 3D Human Modeling Software. Tecmath of North America (2001)

2. Farmer, E., Brownson, A.: Revier of workload measurement, analysis and interpretation methods. European Organisation for the Safety of Air Navigation (2003)

3. Sheng, H.: Modular Arrangement of Predetermined Time Standard. Repute (2009)

4. The Methods and Applications of Fuzzy Math. HUST (2003) 